\title{
Introducing Emotioncy as an Invisible Force Controlling Causal Decisions: A Case of Attribution Theory
}

\begin{abstract}
Given the prominence of studies aimed at determining the factors influencing causal judgments, this study attempts to introduce the newly-developed concept of emotioncy as one of the guiding factors pushing attribution judgments toward a certain spectrum. To this end, two scales of attribution and emotioncy were designed using ten hypothetical situations. A total number of 309 participants filled out the scales. The construct validity of the scales was substantiated through confirmatory factor analysis (CFA). Afterwards, structural equation modeling (SEM) was utilized to examine the possible relationships among the sub-constructs of attribution and emotioncy scales. The results indicated that as the participants' emotioncy level increases, it becomes more likely for them to attribute probable causes to external factors. Moreover, it was revealed that while the involved individuals attribute causes to external factors, the exvolved ones attribute them to internal factors. In the end, implications of the findings were discussed in the realm of judgment and decision making.
\end{abstract}

Key words: emotioncy, judgments, causal attributions, external attribution, internal attribution

\section{Introduction}

One major stream of theory and research on phenomenal causality dates back to the 1960 s when attribution theory was initially introduced through the work of Heider (1958). Since then, a number of studies compiled throughout the history of social psychology were dedicated to discovering other dormant aspects of this prominent theory (Weiner, 2010b). It is very improbable for anyone to discuss interpersonal relationships without knowing about attribution studies (Weiner, 2015). In explaining the behavior of others and their own behavior, people are said to spontaneously attribute the causes of what they see around to internal or external factors involved (Harvey \& Weary, 1984; Heider, 1958).

The fact that almost all individuals are prone to make systematic errors while evaluating the behavior of others or themselves alongside their tendency to fall into the abyss of biases (Onwezen, 2015), and the significance of the effects of one's past causal attributions on one's future decisions (Gollwitzer, Delius, \& Oettingen, 2000; Weiner, 2010b) made the researchers investigate the possible determinants controlling human causal behaviors. In this regard, emotions (Douglas \& Martinko, 2001; Harvey, Martinko, \& Borkowski, 2007; Zeelenberg, Nelissen, Breugelmans, \& Pieters, 2008), prior contact (Corrigan et al., 2001; Corrigan \& Watson, 2002), and schemata (Kelley, 1972) were found to play significant roles in explicating causal behaviors. In fact, it was revealed that the amount of involvement in a particular action seems to have a noteworthy effect on how one attributes possible causes to external or internal factors. It implies that those who are more involved in a situation (by being personally entangled or having prior contact with the target group) feel more empathetic toward the concerned group and have more positive emotions and attitudes toward them than mere observers do (Cayirdag, 2011; Griffin et al., 2008; Read $\&$ Harre, 2001). With regard to the current concerns, the newly designed concept of emotioncy which places much more emphasis on the mixed roles of emotions and sensory schemata (Pishghadam, Tabatabaeyan, \& Navari, 2013), may be rather pertinent in explaining causal behaviors.

Emotioncy, which is a blend of the words emotion and frequency of the exposure to different senses, is defined as

\footnotetext{
* Ferdowsi University of Mashhad, Iran

** Tarbiat Modares University 
the emotions evoked by the senses that can relativize one's cognition (Pishghadam, Jajarmi, \& Shayesteh, 2016). Building upon the idea that sensory data received from past experiences can have a considerable impact on one's perception of future reality (Dewey, 1906), Pishghadam, Jajarmi, et al. (2016) introduced sensory relativism, maintaining that emotions shape one's understanding of reality along with the sensory inputs one receives through senses. In fact, sensory emotioncy deals with merging of sensing (senses), feeling (emotion), and doing (frequency), which is believed to affect our decisions and judgments. From this perspective, sensory emotioncy seems to be highly related to the nature of attribution theory, which deals with individuals' judgments. To be more specific, according to the emotioncy literature, individuals may be avolved (null emotioncy), exvolved (auditory, visual, and kinesthetic emotioncies) or involved (inner and arch emotioncies) toward a particular concept (Pishghadam, 2015), which will be comprehensively defined later. This classification reveals the amount of one's involvement in a specific area, which largely influences the way one perceives reality and understands the world. Therefore, it seems to be justifiable to consider emotioncy as a contributory factor in individuals' judgments and causal behaviors.

Considering sensory experiences can change our understanding of the world (Lakoff \& Johnson, 1980; Pishghadam, Baghaei, \& Seyednozadi, in press) and believing that emotions play a crucial role in forming one's perceptions, judgments, and behaviors (Keltner \& Lerner, 2010; Tiedens \& Linton, 2001), it is our belief that when one has a high level of emotioncy (more involved) for a concept, s/he may display more empathy and understanding for it, hence attributes behaviors to more external and situational factors rather than internal and dispositional ones. With that in mind, our objective in this study is to examine the probable relationships between individuals' attributional styles and their emotioncy types. Therefore, through a quantitative study, we attempt to provide empirical support to see whether being avolved, exvolved, or involved in a situation makes a significant difference in attributing one's behaviors to external or internal factors.

\section{Theoretical Framework}

\section{Attribution Theory}

Through attribution theory, Heider (1958) tried to explain the causes of human behavior and events. He considered common people as naïve scientists who have a broad tendency to weave information together until they come to a reasonable understanding of the surrounding environment. In his opinion, causal attributions answer "why" questions and are driven by internal (dispositional) factors or external (situational) ones. Internal factors are the characteristics which are driven by one's nature, personality, and attitude, whereas external factors are driven by situational elements such as luck and task difficulty. The work of Heider (1958) was later extended by Kelley's (1967) covariation analysis which focused on three sources of information to draw inferences about individual behaviors. The first is consensus which refers to generalizability of the same act in similar situations. The second variable is consistency, which relates to the frequency of the same action over time. The last variable upon which the analysis is drawn is distinctiveness. It accounts for the occurrence of the same behavior in a different situation. Kelley (1967) then linked his model to Heider's (1958) classification by stating that if a behavior is thought to be low in consensus and distinctiveness and high in consistency, it is more likely to be an internal characteristic of an individual (Cayirdag, 2011). Weiner (1986) tried to explain the consequences of attribution by proposing the three dimensional model of locus, stability, and controllability. Locus is defined as the location of the cause, whether it is external or internal in relation to the perceiver. Stability designates the possible changes of that cause over time, and controllability indicates how much that cause is subject to volitional control of the individual. Weiner (2010a) also inferred that the most salient causes of success and failure can be categorized into two main groups of internal and external ones. With regard to the internal factors, ability and aptitude are considered stable and uncontrollable, whereas effort is seen as unstable and controllable. As for the external causes, task difficulty is thought to be stable and controllable while luck is more likely to be unstable and uncontrollable.

A noteworthy point is that while people strive to explain the behavior of human beings, they sometimes fall astray to many biases and errors. One of the most conspicuous biases one might encounter during the attribution process is the fundamental attribution error, which is defined as underestimation of environmental factors and giving more credit to dispositional factors instead (Cayirdag, 2011; Ross, 1977; Weiner, 2015). In a similar vein, hedonic bias, also known as self-serving bias, occurs when individuals take credit for success and attribute the potential causes to their personality traits and assign possible causes for failure to external forces (Bradley, 1978; Cayirdag, 2011; Onwezen, 2015; Zuckerman, 1979). In a similar line of work, it is noted that people in individualistic societies are more inclined to make the fundamental attribution error since they attribute more to internal factors compared to collectivist societies where people are more inclined to make situational attributions and to be more self-effacing (Triandis, 2001). Moreover, different attributional styles and the way through which individuals attribute desirable and undesirable outcomes in their lives have always garnered the attention of attribution theorists (e.g., Cheng \& Furnham, 2001, 2003; Savolainen, 2013; Seligman, Abramson, Semmel, \& Von Baeyer, 1979; Seligman \& Schulman, 1986), and many studies have underscored the role of past interpretations of possible causes for events in making future decisions (Schrader \& Helmke, 2015; Weiner, 2010b, 2015). Therefore, it seems necessary to be cognizant of the factors influencing human judgment and decision making.

As for the most probable source influencing judgmental behavior, the bulk of evidence seems to argue strongly in favor of emotions as hugely affecting individual decisions, 
judgments, and behaviors (Agrawal, Han, \& Duhachek, 2013; De Hooge, Breugelmans, \& Zeelenberg, 2008; Keltner \& Lerner, 2010; Lerner \& Keltner, 2000; Maheswaran \& Chen, 2006; Van der Pligt, 2015). Emotions are also tightly linked to causal beliefs (Weiner, 2010b). Weiner (2010b) and Graham (1991) shed more light on the issue by discussing the case of a teacher who is more likely to become angry with a student when he attributes the cause of student's poor performance to controllable causes such as lack of effort compared to when he attributes the cause to some uncontrollable factors such as aptitude which elicits sympathy. Actor-observer bias seems to be an acceptable theory as it puts forward the idea that individuals' interpretation of causal incidents change as their role shifts from actor to observer or vice versa. Actors are more inclined to make external attributions while observers tend to make more internal attributions (Martinko, Harvey, $\&$ Douglas, 2007). Such attributions may be due to the fact that observers are mere bystanders but actors are personally involved in the experience and can actually feel it (Cayirdag, 2011). In a study by Bernardin (1989), leaders tended to ascribe their employees' failure to dispositional factors while they perceived their own failures to be due to situational factors. In this perspective, researchers posit that the more involved the observers are with the actor and in the action done, the more empathetic their judgments become (Harvey \& Weary, 1984). This claim was proved right in a study by Griffin et al. (2008) where a group of people suffering from flood damage were interviewed. The results showed that people who were angrier with agencies attributed more of the fault to government management (External attribution) than those having had the experience of living in floodplains. The latter group felt more empathetic toward government officials and was, as a result, less furious with them. In addition, Kelley's (1972) notion of causal schemata seems to be pertinent to the matter. A schema allows the attributor to make better inferences about the cause involved. It seems that the roles of emotions and schemata in attributional processes are still open to investigation. In the following section, the basic conceptions of the newly designed notion of emotioncy are viewed. Emotioncy takes both of these crucial components into account.

\section{Emotioncy}

Emotion, as the crucial link in explicating the true nature of causal judgments, is the main focus of Greenspan's (1992) developmental individual-difference relationship-based (DIR) model in which he puts emphasis on the affective domains, supportive relationships, and family functions. Building upon what Greenspan (1992) presented in his DIR model, Pishghadam, Tabatabaeyan, et al. (2013) introduced the new concept of emotioncy and defined it as emotions evoked by the senses which can relativize one's cognition. In the field of language education, Pishghadam, Tabatabaeyan, et al. (2013) and Pishghadam and Shayesteh (2016) are of the view that establishing emotional connections provides meaningfulness, and facilitates the process of second/ foreign language learning. They also claim that the more emotional engagement with a text one has, the more comprehensibility s/he can achieve. Furthermore, contrary to Piaget's (1926) schema theory which underscores the role of prior knowledge in information processing, Pishghadam, Adamson, and Shayesteh (2013) delved deeper into the issue and propounded the significant role of emotions in making meaning of the world. In a similar manner, Matthews (1992) asserted that one's ultimate perception of the world is a result of his/her sensory experiences. Moreover, Dewey (1906) stated that what one experiences in the past paves the way for his/her conception of reality. In a similar vein, Pishghadam, Jajarmi, et al. (2016) recommended sensory constructivism to delineate the way sensory emotions shape individual's perception of the world.

To elaborate, Pishghadam (2015) proposes a metric for measuring an individual's emotioncy toward a particular concept. According to this metric, individuals may have not the slightest idea of a word or concept (null emotioncy), they may have only heard about of the word (auditory emotioncy), they may have heard about and seen it (visual emotioncy), they may have heard about, seen, and touched it (kinesthetic emotioncy), they may have gone through the experience directly (inner emotioncy), and they may have gone through all of the above states, and have also researched deeply on the subject (arch emotioncy). In fact, the model is hierarchical and incremental as depicted in the illustration (Figure 1), and individuals move along a continuum of avolvement (null emotioncy), exvolvement (auditory, visual, and kinesthetic emotioncies), and involvement (inner and arch emotioncies) through the processes of emotionalization.

In an interview conducted by Pishghadam, Jajarmi, et al. (2016), people demonstrated different cognitive and emotional reactions toward the concept of phlebotomy according to their level of emotionalization toward the concept. It was revealed that people who were exvolved with regard to the concept in question expressed more exaggerated emotions and were more distant from reality. In fact, they had created hyper/hypo realities and had more distal emotions while the participants who had gone through the procedure themselves and had done research on it expressed less exaggerated emotions (proximal emotions) and were closer to reality. Therefore, it seems quite reasonable that no matter what one perceives from the meaning of a word, his/her worldview and the way $\mathrm{s} / \mathrm{he}$ forms realities in his/her mind are definitely influenced by his/her amount of exvolvement or involvement in the case.

To shed more light on the concept, Pishghadam, Adamson, et al. (2013) provided an example of an Iranian student living in northern areas who can have a better understanding of words such as jungle and rain compared to the student living in southern regions, probably because the southern person has had little or no encounter with such concepts before and does not have the experience of living in such an environment. Hence, having little or no emotional engagement with the mentioned concepts, his understanding of such concepts would be like living in a bubble and being a mere observer who has not had the experience of taking part in the action. In a similar line of 
Figure 1. Emotioncy Levels

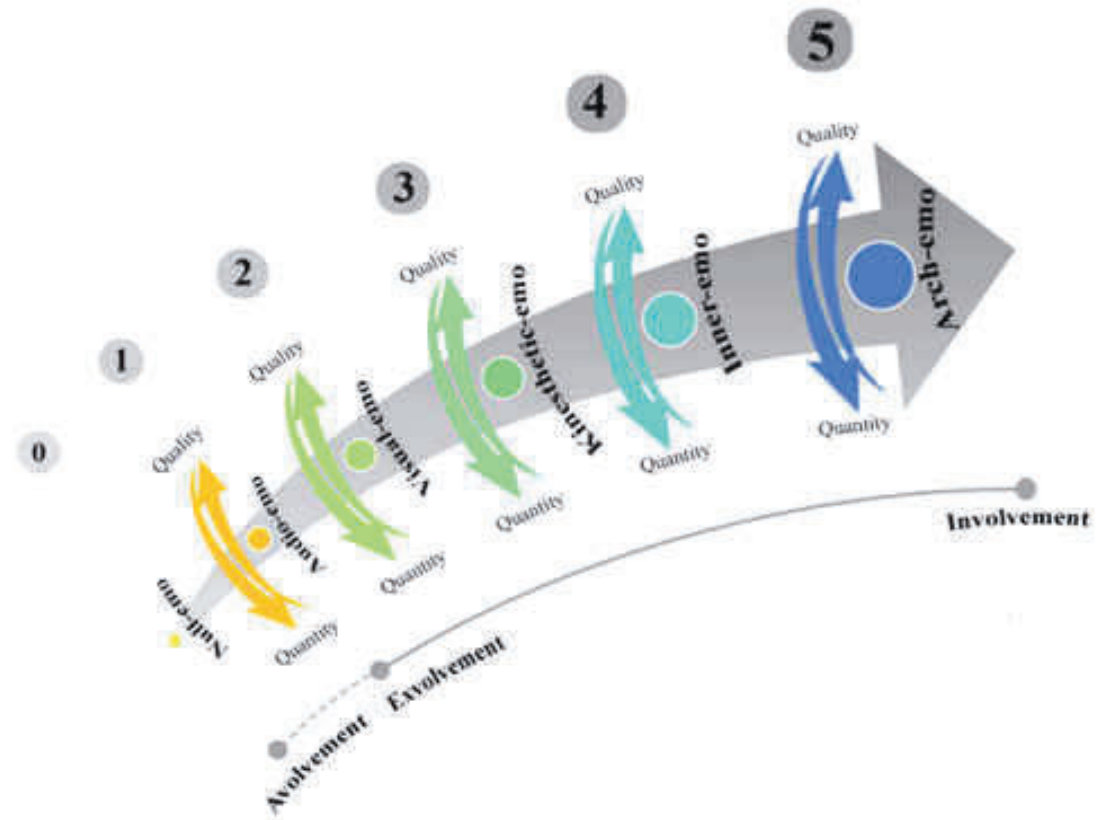

Adapted from "Emotioncy in Language Education: From Exvolvement to Involvement", By R. Pishghadam, 2015, October, Paper presented at the 2nd Conference of Interdisciplinary Approaches to Language Teaching, Literature, and Translation Studies. Iran, Mashhad.

work, Corrigan and Penn (1999) introduced prior contact as the most promising strategy in reducing individuals' prejudiced attitudes toward those suffering from mental illnesses. Those in touch with mental patients were less likely to stigmatize them. Having close encounter was found to lead to generating more emotional responses and perceiving less social distance. Given the similarity of Corrigan and Penn's (1999) contact strategy in reducing stigmatized beliefs with Pishghadam's (2015, 2016b) notion of involvement and the significance of continued work in this regard due to the limitations of previous studies (Corrigan, Morris, Michaels, Rafacz, \& Rüsch, 2012; Couture \& Penn, 2003), emotioncy, as a notion amalgamating sensory schemata, prior contact, and emotional intensity, seems to be a good joint to invest in for explaining the hidden forces moving individuals toward making a particular judgment. In fact, it is the authors' hypothesis that being avolved, exvolved, or involved in a situation has a considerable effect on the way people attribute the causes of an event to external or internal factors. In order to delineate the point, the present study attempts to investigate any probable relationship between people's attribution style (with regard to the locus dimension of Weiner's (1986) theory) and their emotioncy type. In fact, the current study attempts to find the answers to the following questions:

1. Are there any significant relationships between avolvement/exvolvement/involvement and internal attribution?

2. Are there any significant relationships between avolvement/exvolvement/involvement and external attribution?

\section{Methodology}

\section{Participants}

A total number of 309 individuals from Iran participated in the current study. The sample comprised 179 females and 130 males with a mean age of 27.3 years $(\mathrm{SD}=6.9)$, ranging from 18 to 46 . They were selected based on convenience sampling, because having access to all the people in the target population was not feasible and as a result, it was almost improbable to use probability sampling. With regard to their educational background, 127 members had received higher education (Masters /Ph.D.), 101 had undergraduate degrees, and 81 participants were high school graduates. Their jobs ranged from selfemployed and non-workers such as students to governmental employees. They were contacted in person by the authors who provided them with a thorough explanation of the research procedure. They were also asked to be willing to cooperate beforehand, and they were ensured that their responses were fully confidential since the scales did not require their names. It should also be mentioned that the participants came from diverse socioeconomic status.

\section{Procedure}

The attribution and emotioncy scales were devised prior to data collection procedure. Prior to this, the review of the related literature and methodological issues were fully examined. The face validity and content validity of the employed scales were approved by experts of educational psychology. Then, both of the scales were piloted with a number of individuals, and some modifications were made to assure the comprehensibility of the written scales, 
such as paraphrasing some sentences. Afterwards, the scales were piloted with 4 individuals and proved understandable. Thereafter, based upon participants' willingness to cooperate, attribution scale was administered to them first, and then the emotioncy scale in order to control the bias which might influence their true judgments in the first scale. The scales were fully explained to them to assure their understanding of the instructions. Since the scales did not require any names to be written and were distinguished from each other by a code number, the participants were not worried about the confidentiality of their responses. It took 15-20 minutes for them to fill out both scales.

As for data analysis, the reliability of the scales was investigated via Cronbach's alpha, SPSS (Version 23). Moreover, to substantiate the construct validity of the scales, confirmatory factor analysis (CFA) was performed using Amos (Version 18). In the end, the relationships among the latent variables were examined through structural equation modeling (SEM).

\section{Instruments}

\section{Attribution Scale}

To determine the respondents' attributional style, we designed a new scale. Based on the literature review, it was found that pure open-ended questions could not be as reliable as the fixed-format ones (Elig \& Frieze, 1979). Likewise, the reliability of pure fixed-format version questionnaires for determining individuals' attributional style was also under question (Peterson et al., 1982). The authors were of the idea that the best compromise may be to devise a scale which is fixed formatted and open to negotiation at the same time; that is to say, one which permits respondents to incorporate their personal opinions into the stated options. Having this notion in mind and having gained enough insight from the abovementioned literature, we designed a 10 item attribution scale measuring 10 hypothetical situations (e.g., smoking, driving, etc.). In the end, the participants were asked to select what the possible cause of the incident might be. The scale was written in participants' mother tongue, Persian, in order to be thoroughly comprehensible. It is also worth mentioning that the authors gained insight from previously validated measures in this regard (e.g., Peterson et al., 1982; Seligman et al., 1979), but the items were not derived from any special scale. For instance, items were framed within the following presentation: "Your exam scores are announced, and your friend has got a low score, though s/he had studied hard. What do think the possible causes might be?" Given that this study is the first of its kind in the field, the authors attempted to limit their scope of attention to only one aspect of Weiner's (1986) theory which better suits the emotioncy model for preliminary investigations. Therefore, disregarding the stability and controllability dimensions of Weiner's theory (1986), we focused on the locus dimension of Weiner's model of attribution. Hence, one of the proposed options for the causes of each hypothetical situation under question was addressing internal factors and the other targeted the external/situational forces in control. To reduce the force in selecting one of the options, the participants were asked to state their agreement with regard to both of the suggested causes for each situation based on a 5-point Likert scale ranging from 1 (strongly disagree) to 5 (strongly agree). As for the abovementioned example, the two proposed causes were (a) s/he is not very bright; (b) the professor seems to have had an ax to grind with the student and has given him/her a low mark (see Appendix 1).

\section{Emotioncy Scale}

According to the metric of emotioncy levels proposed by Pishghadam (2015), a 10 item emotioncy scale was devised by the researchers which tapped the participants' emotioncy score with regard to the hypothetical situations already introduced to the respondents through attribution scale (Appendix 2). Null, auditory, visual, kinesthetic, inner, and arch emotioncies were put into words for each hypothetical situation. The metric comprised three parts: the sense aspect (including null $=0$ point, auditory $=1$ point, visual $=2$ points, kinesthetic $=3$ points, inner $=4$ points, and $\operatorname{arch}=5$ points), the emotion aspect (their feelings toward the hypothesized situation, ranging from extremely positive to extremely negative based on a 5-point Likert scale), and the frequency aspect which aimed to measure their amount of exposure to the situation. Then, the total emotioncy scores were calculated by multiplying the sense score by the summation of emotion and frequency scores. Therefore, Emotioncy $=$ sense $($ emotion + frequency). Now imagine a person has filled out the emotioncy scale for the aforementioned example as: I have got a low score on an exam, though I had studied hard (sense score $=4$ ). Ifeel bad about it (emotion score $=2$ ) and this has occurred to me very much (frequency score $=5$ ). His total emotioncy score would be 28 (See Figure 2).

\section{Results}

\section{Validation}

The researchers confirmed the construct validity of both of the utilized scales through the use of CFA.

\section{Attribution Scale}

Figure 3 demonstrates the proposed model for attribution scale used in this study which is comprised of two latent variables, namely external and internal, and ten dependent variables for each of them. In order to estimate fit of the model, goodness of fit indices were calculated using Amos. As illustrated in Table 1, the relative chi-square which is computed through the division of chi-square by the degrees of freedom $\left(\chi^{2 / d f}\right)$, Goodness of Fit Index (GFI), Tucker-Lewis Index (TLI), Comparative Fit Index (CFI), and Root Mean Square Error of Approximation (RMSEA) are utilized in this study. As reported in the studies, $\chi^{2} d f$ should be less than 3 , TLI, GFI, and CFI should be above .90, and RMS should be less than .08 in order to meet the acceptance criteria (Browne \& Cudeck, 1993; Hu \& Bentler, 1999). As it is shown in Table 1, all of the calculated indices are proved admissible. Therefore, the validation of the designed attribution scale is substantiated by the use of CFA. In addition, the reliability of attribution scale was .89 , calculated by Cronbach's alpha. 
Figure 2. A Metric for Measuring Emotioncy

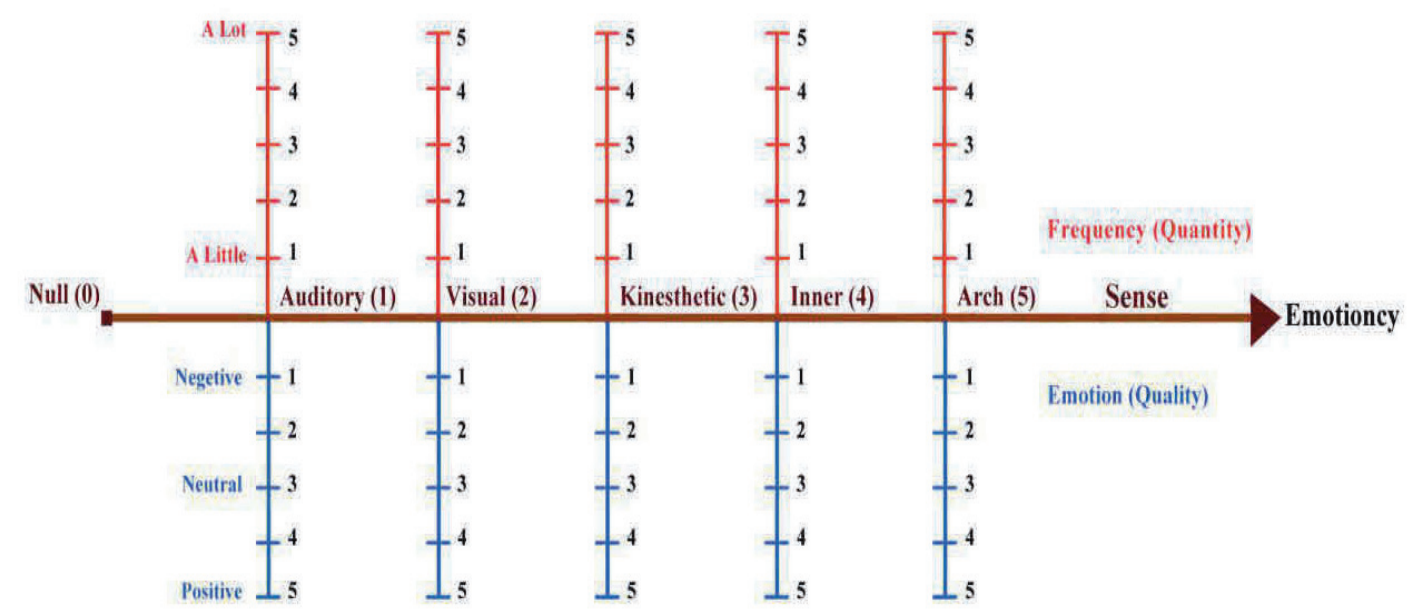

Adapted from "Emotioncy, extraversion and anxiety in willingness to communicate in English" By R. Pishghadam, 2016a, May, Paper presented at the $5^{\text {th }}$ International Conference on Language, Education and Innovation. England: London.

Figure 3. Validity of the Attribution Scale

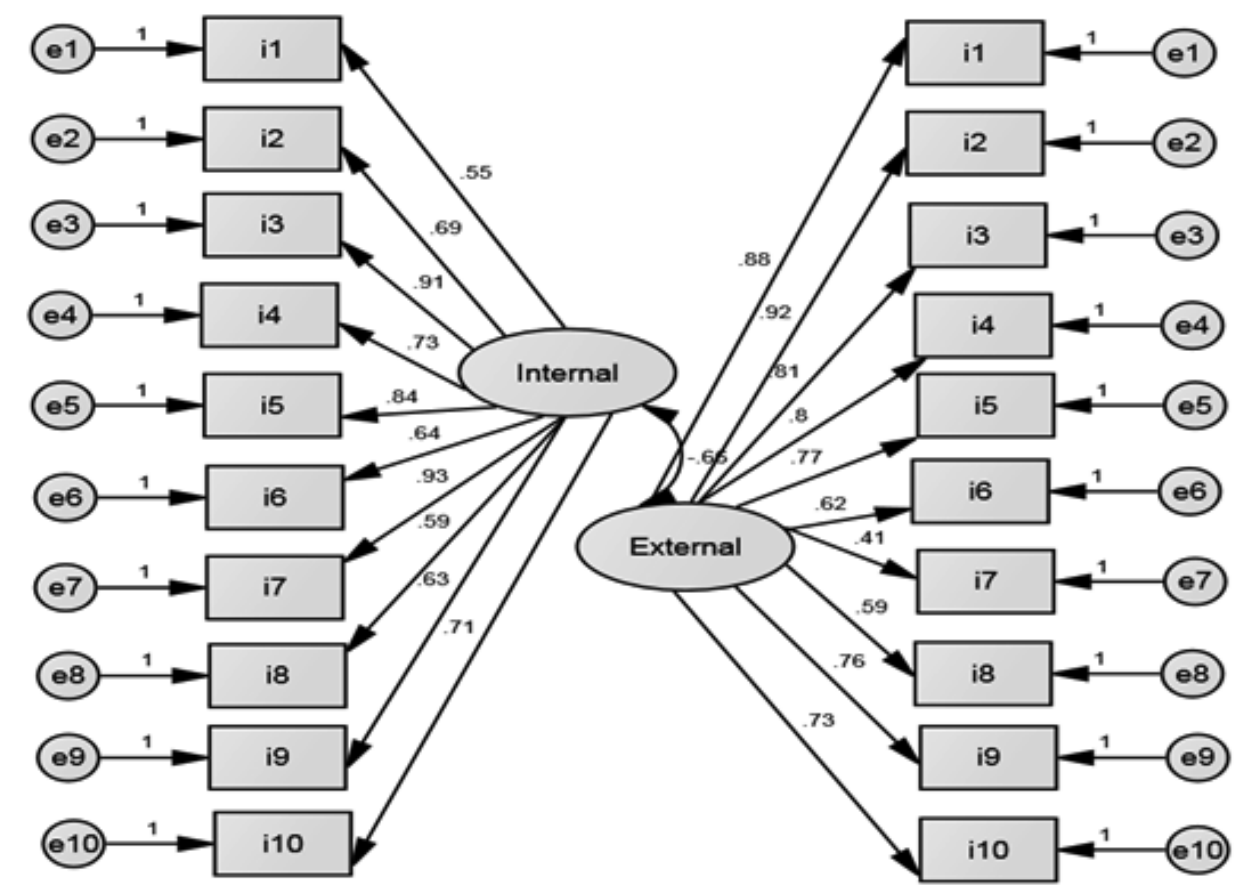

Table 1. Goodness of Fit Indices for the Scales

\begin{tabular}{cccccc}
\hline Fit index & $\boldsymbol{\chi}^{2} / \boldsymbol{d} \boldsymbol{f}$ & GFI & TLI & CFI & RMSEA \\
\hline Attribution model & 2.66 & .931 & .90 & .91 & .04 \\
\hline Emotioncy model & 2.11 & .92 & .93 & .91 & .05 \\
\hline
\end{tabular}

\section{Emotioncy Scale}

A model with two factors (frequency and emotion) and ten items was developed through CFA (Figure 4). The model designated 10 potential dependent variables for each of the factors. The figures on the arrows represent the significance of the existing correlations. Once again, the indices were inspected to assure fit of the model. The results of the inspection depicted in Table 1 proved satisfactory for the structure of the scale, hence validation of the employed scale was verified. Moreover, the internal consistency of the emotioncy scale computed through Cronbach's alpha was .84.

\section{Descriptive Statistics and Correlations}

This study intended to validate two measures for participants' attributional styles and emotioncy types with regard to ten hypothetical situations one might come up in 
Figure 4. Validity of the Emotioncy Scale

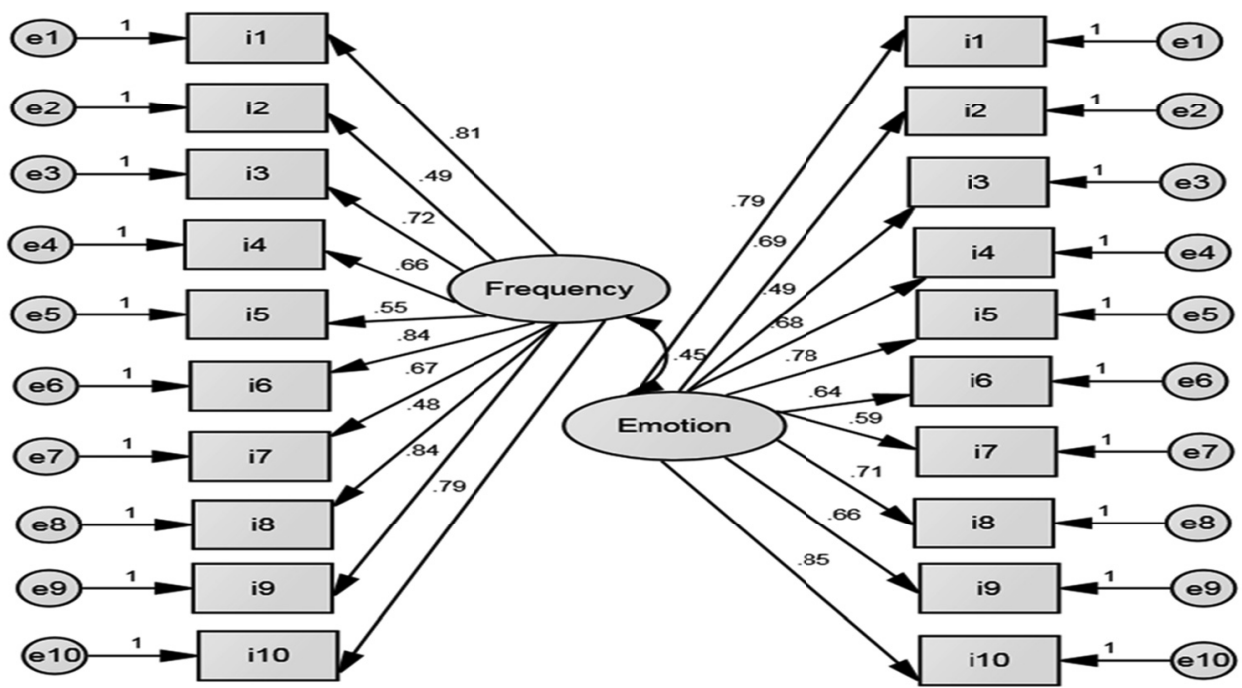

a real life situation. Table 2 shows the results of descriptive statistics as well as the Pearson product-moment correlation among the variables.

As Table 2 shows, emotioncy is negatively related to internal factors $(\mathrm{r}=-.11, p<.05)$. That is to say, the higher the emotioncy score is, the less likely participants are to attribute causes to internal factors. Under close scrutiny, exvolvement is revealed to be negatively related to external factors $(\mathrm{r}=-.29, p<.05)$ while there is a positive relationship between exvolvement and internal factors $(\mathrm{r}=.38, p<.05)$, implying that the more exvolved a person is with the encountered situation, the less likely s/ he is to attribute possible causes to external factors. Along the same lines goes the negative relationship between involvement and internal factors $(r=-.22, p<.05)$ and the positive relationship between of involvement and external factors $(\mathrm{r}=.31, p<.05)$. This espouses the idea that the more involved the participants are in a situation, the less likely they are to attribute the possible causes to internal characteristics, and the more inclined they are to see external/situational forces in control.

\section{The Model Proposed by SEM}

In order to investigate the legitimacy of the theoretical hypothesis of the current study, SEM was deployed to examine any likely relationship between attribution and emotioncy scales. As depicted in Figure 5, avolvement (null emotioncy), exvolvement (including auditory, visual, and kinesthetic emotioncies), and involvement (including inner and arch emotioncies) are introduced as latent variables of emotioncy, which is itself comprised of two dependent variables, frequency and emotion. The model proposes that there is a significant relationship between emotioncy and external factors $\left(\mathrm{R}^{2}=.32\right)$ but the relationship between emotioncy and internal factors is negative and nonsignificant $(\mathrm{R}=-.03)$. In fact, emotioncy accounts for $10 \%$ of variance in internal attribution. The contribution of exvolvement as a latent variable of emotioncy is also significant. The model suggests that exvolvement correlates positively with internal factors $\left(\mathrm{R}^{2}=.31\right)$ and accounts for almost $10 \%$ of variance in that; but it correlates negatively with external factors $\left(\mathrm{R}^{2}=-.21\right)$, accounting for $4 \%$ of variance in internal attribution. Moreover, involvement, as

Table 2. Descrptive Statistics and Correlations for the Variables

\begin{tabular}{llllllll}
\hline Variables & Mean (SD) & 1 & 2 & 3 & 4 & 5 & 6 \\
\hline 1. Avolvement & $.72(.23)$ & 1 & & & & & \\
2. Exvolvement & $6.1(1.2)$ & .08 & 1 & & & & \\
3. Involvement & $3.1(1.9)$ & .06 & $-.41^{* *}$ & 1 & & & \\
4. Emotioncy & $141(16.3)$ & .06 & $.43^{* *}$ & $.52^{* *}$ & 1 & & \\
5. Internal & $29.3(4.9)$ & .08 & $.38^{* *}$ & $-.22^{* *}$ & $-.11^{*}$ & 1 & \\
6. External & $31.2(3.4)$ & .02 & $-.29^{* *}$ & $.31^{* *}$ & $.42^{* *}$ & $-.78^{* *}$ & 1 \\
\hline
\end{tabular}

${ }^{*} p<.05 \quad{ }^{* *} p<.01$


Figure 5. Model of the Relationship between Emotioncy and Attribution

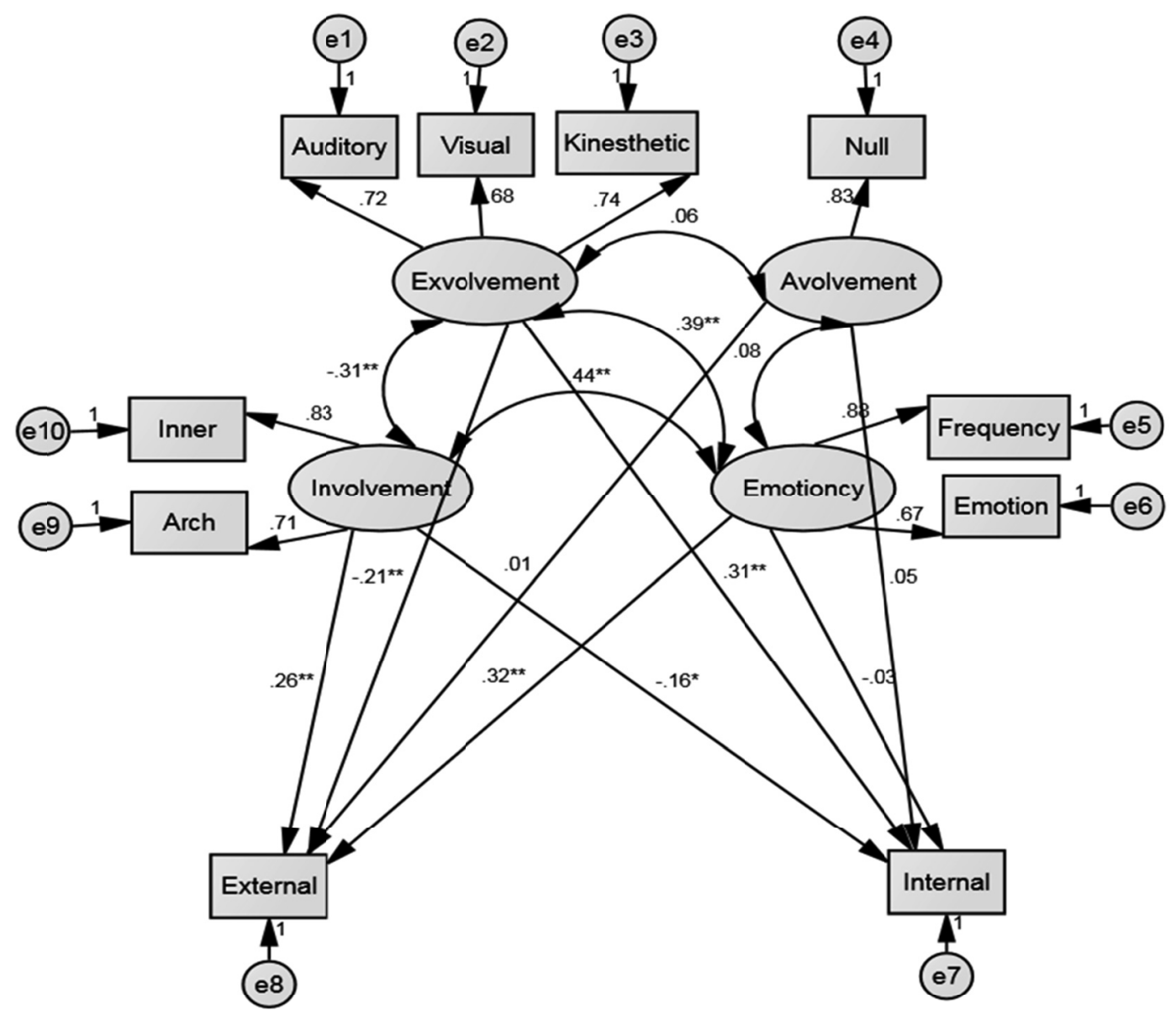

another latent variable of emotioncy, is positively related to external factors $\left(\mathrm{R}^{2}=.26\right)$, which accounts for almost $7 \%$ of variance in external attribution, while it is negatively related to internal factors $\left(\mathrm{R}^{2}=-.16\right)$, accounting for almost $3 \%$ of variance in that. Moreover, no relationship was found between avolvement and internal $\left(\mathrm{R}^{2}=.05\right)$ or external $\left(\mathrm{R}^{2}=.01\right)$ attributions.

To ascertain the suitability of the proposed model, goodness of fit indices were checked. Table 3 displays the obtained results which are congruent with the acceptable criteria.

Table 3. Goodness of Fit Indices

\begin{tabular}{cccccc}
\hline Fit index & $\boldsymbol{\chi}^{2} / \boldsymbol{d} \boldsymbol{f}$ & GFI & TLI & CFI & RMSEA \\
\hline Model & 1.89 & .90 & .92 & .94 & .06 \\
\hline
\end{tabular}

\section{Discussion}

Considering the impact of biases on human judgment and decision making (Pronin, 2007), and knowing that emotions, prior contact, and prior schemata contribute significantly to shaping individuals' judgments and behaviors (Corrigan \& Penn, 1999; Kelley, 1972; Keltner \& Lerner, 2010; Tiedens \& Linton, 2001), this study attempted to discover the unnoticed influence of emotioncy in explaining causal judgments. In this regard, our primary contribution was to devise and validate scales for measuring one's attributional style (based on the locus dimension of Weiner's (1986) theory) and emotioncy level toward the situations. The scales were utilized to investigate any likely relationship between the sub-constructs of the two scales, namely internal and external factors and avolvement, exvolvement, and involvement variables, from the attribution and emotioncy scales, respectively.

In the first phase of the study, both of the devised scales were validated by the use of CFA. The results of CFA for the attribution scale confirmed the model fit, indicating that the items appropriately contributed to the model. There were two latent variables identified in this model, namely internal and external; and these variables correlated significantly to the proposed choices for each item. As for the emotioncy scale, the results of CFA confirmed the two independent variables of emotion and frequency, indicating that for each item, the respondents' amount of exposure and the valance of their emotions were evaluated, and then added up to yield a total estimate of one's emotioncy score. The picture drawn confirmed fit of the model, hence the construct validity of the scales.

Regarding the second phase of the study, SEM was used to probe the possible relationships among the subconstructs of the two scales. At first glance, it can be 
deduced that apart from having no emotional engagement with the situation (null emotioncy), people's emotioncy toward different situations comes from outside of an individual and through auditory, visual, and kinesthetic emotioncies or originates from inside an individual (inner and arch emotioncies). The two sided arrows between avolvement and exvolvement, and also from exvolvement to involvement confirm what Pishghadam (2015) and Pishghadam, Jajarmi, et al. (2016) propounded in their study that individuals can constantly move from one emotioncy level to the other one through the processes of emotionalization and de-emotionalization.

One of the most prominent relations proposed by this model is the significant positive correlation between the emotioncy score and the external variable. If senses are the origins of knowledge (Matthews, 1992), then it is quite reasonable that the emotions provoked by our sensory experiences shape the way we perceive the world (Pishghadam, Shayesteh, \& Rahmani, 2016; Pishghadam, Jajarmi, et al., 2016). In a similar vein, it seems plausible that the more emotionalized a person is with regard to a situation, the better $\mathrm{s} / \mathrm{he}$ can come to an understanding of the diverse causes which might go hand in hand and make it happen. In fact, individuals mold different forms of realities based on their amount of exvolvement or involvement in the situation. In other words, exvolved people create hypo/ hyper realities while the involved individuals' perception of reality is much closer to the reality itself (Pishghadam, Jajarmi, et al., 2016). That is to say, "The density of the emotional nexus for an experience can determine the individual's proximity to reality" (p. 19).

Moreover, the outcomes of the study showed no relationship between avolvement and internal or external attributions. This finding is justifiable when we know that avolvement (null emotioncy) implies that the person does not know what the situation or entity is, hence no emotions are generated. It is no surprise that when one has not experienced something and has no emotion for that, judgments would not be much affected by internal or external factors.

Quite analogous to the above findings, we can find an appropriate answer to the two queries of our study by scrutinizing the model (Figure 5). The positive correlation between exvolvement and internal factors and the negative correlation between exvolvement and external factors from one side, and similarly, the positive correlation between involvement and external factors and the negative correlation between involvement and internal factors from the other, are totally congruent with the researchers' assumptions. These findings indicate that the more involved a person is in a situation, the less s/he is likely to attribute causes to dispositional characteristics. One likely justification may be that, due to the fact that the exvolved participants are not completely drowned in an experience and their understanding of the concept may be illusionary, just like a person living in a bubble and reaching for the experience from inside the bubble, who will therefore rarely grasp the reality of the concept seeing as one has no idea about the environmental factors affecting the concept. The distal nature of one's emotions leads to the formation of a hypo/hyper reality based on the person's inaccurate, if not non-existing, background. On the contrary, the involved participants focused on the reality itself. These findings are in line with those of Pishghadam, Jajarmi, et al.'s study (2016). In essence, this viewpoint is compatible with that of Van der Pligt's (2015), based on which the probability of an event is overestimated in our minds if we can remember the concrete instances of such events. Therefore, if one has experienced being in a serious car accident, he will remember the case better compared to the time he has only read about accident statistics. In the case of our study, the involved participants could remember the case of external options and could empathize more with the ones having gone through an incident probably because they could remember the time they could/could not make something due to a situational factor involved. As a result, they could agree more than the ones not having had the same experience that an external force might be at work, and so not attribute the possible cause to internal factors immediately. An instance from the present study can elucidate the point. The participants were asked to comment on the behavior of a driver who blocks the way for other drivers in a highway. The ones more exvolved in such a case voted for the driver to be reckless, while the ones who happened to have behaved in the same way at some point voted that a problem might have made the person behave so. For example, he might have been forced to do so because he wanted to take a patient to the hospital urgently. Still, another line of justification might be the existence of self-serving bias (Cayirdag, 2011), which can very well be a way of explaining away one's behavior, and a method for resolving cognitive dissonance by attributing the behavior as outside of oneself rather than having to take ownership for one's actions.

On the whole, it is important to be cognizant of the fact that individuals are unconsciously entrapped by biases and blinded by their impacts (Pronin, 2007). It is, therefore, of utmost importance to recognize the prevailing errors and biases and set out to remedy them. Failing to recognize such common prejudices influencing human judgments in different situations averts the chance to correct them (Pronin, 2007). In this light, the present study attempted to make us aware of emotioncy as an unnoticed vim pushing causal judgments toward a certain spectrum. In fact, by keeping the role of emotioncy in mind, people may rethink stereotyping and question the genuineness of the possible cause coming to one's mind. In a similar manner, knowing that higher levels of emotioncy lead to more understanding of an issue, one might be more attentive in making decisions such as assigning someone who is more involved in that issue to a certain position wherein his or her broader view helps him/her inspect overlooked aspects. Thus, the implication of the data proves useful for a broad range of contexts.

In short, the outcomes obtained from this study showed that emotioncy can be one of the dormant determinants influencing our causal decisions. To acknowledge that those who conduct a study are not 
oblivious to its limitations, the researchers are of the view that the findings of the current study should be confirmed through a qualitative study as well. Since this study made use of two experimenter created measures, caution should be exercised in generalization of the findings. Moreover, the present study examined individuals' attributional style by emphasizing the locus dimension of Weiner's (1986) model, other studies can be conducted to investigate the effect of emotioncy on other aspects of his theory.

\section{References}

Agrawal, N., Han, D., \& Duhachek, A. (2013). Emotional agency appraisals influence responses to preference inconsistent information. Organizational Behavior and Human Decision Processes, 120(1), 87-97. http://dx.doi.org/ 10.1016/j.obhdp.2012.10.001

Bernardin, H.J. (1989). Increasing the accuracy of performance measurement: A proposed solution to erroneous attributions. Human Resource Planning, 12, 239-250.

Bradley, G.W. (1978). Self-serving biases in the attribution process: A reexamination of the fact or fiction question. Journal of Personality and Social Psychology, 36(1), 56-71.

Browne, M.W., \& Cudeck, R. (1993). Alternative ways of assessing model fit. In K.A. Bollen \& J.S. Long (Eds.), Testing structural equation models (pp. 136-162). CA: Sage.

Cayirdag, N. (2011). Attribution and creativity. In M.A. Runco \& S.R. Pritzker (Eds.), Encyclopedia of creativity (2nd ed., pp. 96-100). Cambridge: Academic Press.

Cheng, H., \& Furnham, A. (2001). Attributional style and personality as predictors of happiness and mental health. Journal of Happiness Studies, 2(3), 307-327.

Cheng, H., \& Furnham, A. (2003). Attributional style and self-esteem as predictors of psychological well being. Counselling Psychology Quarterly, 16(2), 121-130.

Corrigan, P.W., Morris, S.B., Michaels, P.J., Rafacz, J.D., \& Rüsch, N. (2012). Challenging the public stigma of mental illness: A metaanalysis of outcome studies. Psychiatric Services, 63, 963-973.

Corrigan, P.W., \& Penn, D.L. (1999). Lessons from social psychology on discrediting psychiatric stigma. American Psychologist, 54(9), 765-776.

Corrigan, P.W., River, L.P., Lundin, R.K., Penn, D.L., Uphoff-Wasowski, K., Campion, J., ... Kubiak, M.A. (2001). Three strategies for changing attributions about severe mental illness. Schizophrenia Bulletin, 27(2), 187-195.

Corrigan, P.W., \& Watson, A.C. (2002). Understanding the impact of stigma on people with mental illness. World Psychiatry, 1(1), 16-20.

Couture, S., \& Penn, D. (2003). Interpersonal contact and the stigma of mental illness: A review of the literature. Journal of Mental Health, 12(3), 291-305.

De Hooge, I.E., Breugelmans, S.M., \& Zeelenberg, M. (2008). Not so ugly after all: When shame acts as a commitment device. Journal of Personality and Social Psychology, 95(4), 933-943. http://dx.doi. org/10.1037/a0011991

Dewey, J. (1906). Studies in logical theory. Chicago, IL: The University of Chicago Press.

Douglas, S.C., \& Martinko, M.J. (2001). Exploring the role of individual differences in the prediction of workplace aggression. Journal of Applied Psychology, 86, 547-559.

Elig, T.W., \& Frieze, I.H. (1979). Measuring causal attributions for success and failure. Journal of Personality and Social Psychology, 37, 621-634.

Gollwitzer, P.M., Delius, J.D., \& Oettingen, G. (2000). Motivation. In K. Pawlik, \& M.R. Rosenzweig (Eds.), International handbook of psychology (pp. 191-206). London, UK: Sage.

Graham, S. (1991). A review of attribution theory in achievement contexts. Educational Psychology Review, 3(1), 5-39.

Greenspan, S.I. (1992). Infancy and early childhood: The practice of clinical assessment and intervention with emotional and developmental challenges. Madison, CT: International Universities Press.
Griffin, R.J., Yang, Z., ter Huurne, E., Boerner, F., Ortiz, S., \& Dunwoody, S. (2008). After the flood. Anger, attribution, and seeking of information. Science Communication, 29(3), 285-315.

Harvey, P., Martinko, M.J., \& Borkowski, N. (2007, March). Unethical behavior among physicians and students: Testing an attributional and emotional framework. Paper presented at the 2007 Academy of Management Conference, Philadelphia, PA.

Harvey, J.H., \& Weary, G. (1984). Current issues in attribution theory and research. Annual Review of Psychology, 35(1), 427-459.

Heider, F. (1958). The psychology of interpersonal relations. New York: Wiley.

Hu, L.T., \& Bentler, P.M. (1999). Cutoff criteria for fit indexes in covariance structure analysis: Conventional criteria versus new alternatives. Structural Equation Modeling, 6, 1-55. http://dx.doi. org/10.1080/10705519909540118

Kelley, H.H. (1967). Attribution theory in social psychology. In D. Levine (Ed.), Nebraska symposium on motivation (pp. 192-238). Lincoln: University of Nebraska Press.

Kelley, H.H. (1972). Causal schemata and the attribution process. Morristown, NJ: General Learning Press.

Keltner, D. \& Lerner, J.S. (2010). Emotion. In D.T. Gilbert, S.T. Fiske, \& G Lindzey (Eds.), The handbook of social psychology (pp. 317-352). New York: Wiley.

Lakoff, G., \& Johnson, M. (1980). The metaphorical structure of the human conceptual system. Cognitive Science, 4(2), 195-208.

Lerner, J.S., \& Keltner, D. (2000). Beyond valence: Toward a model of emotion-specific influences on judgement and choice. Cognition \& Emotion, 14(4), 473-493, http://dx.doi.org/10.1080/026999300402763

Maheswaran, D., \& Chen, C.Y. (2006). Nation equity: Incidental emotions in country-of-origin effects. Journal of Consumer Research, 33(3), 370-376. http://dx.doi.org/10.1086/508521

Martinko, M.J., Harvey, P., \& Douglas, S.C. (2007). The role, function, and contribution of attribution theory to leadership: A review. The Leadership Quarterly, 18(6), 561-585.

Matthews, M. (1992). Constructivism and empiricism: An incomplete divorce. Research in Science Education, 22, 299-307.

Onwezen, M.C. (2015). I did good, and we did bad: The impact of collective versus private emotions on pro-environmental food consumption. Food Research International, 76, 261-268.

Peterson, C., Semmel, A., Von Baeyer, C., Abramson, L.Y., Metalsky, G.I., \& Seligman, M.E. (1982). The attributional style questionnaire. Cognitive Therapy and Research, 6(3), 287-299.

Piaget, J. (1926). The language and thought of the child. London: Routledge and Kegan.

Pishghadam, R. (2015, October). Emotioncy in language education: From exvolvement to involvement. Paper presented at the 2 nd Conference of Interdisciplinary Approaches to Language Teaching, Literature, and Translation Studies, Mashhad, Iran.

Pishghadam, R. (2016a, May). Emotioncy, extraversion and anxiety in willingness to communicate in English. Paper presented at the $5^{\text {th }}$ International Conference on Language, Education and Innovation, London, Englan.

Pishghadam, R. (2016b, September). Introducing emotioncy tension as a potential source of identity crisis. Paper presented at the $16^{\text {th }} \mathrm{In}$ terdisciplinary Conference on Cultural Identity and Philosophy of the Self, London, Englan.

Pishghadam, R., \& Abbasnejad, H. (2016). Emotioncy: A potential measure of readability. International Electronic Journal of Elementary Education, 9(1), 109-123.

Pishghadam, R., Adamson, B., \& Shayesteh, S. (2013). Emotion-based language instruction (EBLI) as a new perspective in bilingual education. Multilingual Education, 3(9), 1-16.

Pishghadam, R., Baghaei, P., \& Seyednozadi, Z. (in press). Introducing emotioncy as a potential source of test bias: A mixed Rasch modelling study. International Journal of Testing.

Pishghadam, R., Jajarmi, H., \& Shayesteh, S. (2016). Conceptualizing sensory relativism in light of emotioncy: A movement beyond linguistic relativism. International Journal of Society, Culture \& Language, 4(2), 11-21.

Pishghadam, R., \& Shayesteh, S. (2016). Emotioncy: A post-linguistic approach toward vocabulary learning and retention. Sri Lanka Journal of Social Sciences, 39(1), 27-36. 
Pishghadam, R., Shayesteh, S., \& Rahmani, S. (2016). Contextualizationemotionalization interface: A case of teacher effectiveness. International and Multidisciplinary Journal of Social Sciences (RIMCIS), $5(2), 97-127$.

Pishghadam, R, Tabatabaeyan, M.S., \& Navari, S. (2013). A critical and practical analysis of first language acquisition theories: The origin and development. Iran, Mashhad: Ferdowsi University of Mashhad Publications.

Pronin, E. (2007). Perception and misperception of bias in human judgment. Trends in Cognitive Sciences, 11(1), 37-43.

Read, J., \& Harre, N. (2001). The role of biological and genetic causal beliefs in the stigmatization of 'mental patients'. Journal of Mental Health UK, 10, 223-235.

Ross, L. (1977). The intuitive psychologist and his shortcomings: Distortions in the attribution process. Advances in Experimental Social Psychology, 10, 173-220.

Savolainen, R. (2013). Approaching the motivators for information seeking: The viewpoint of attribution theories. Library \& Information Science Research, 35(1), 63-68.

Schrader, F.W., \& Helmke, A. (2015). School achievement: Motivational determinants and processes. In J.D. Wright (Ed.), International encyclopedia of the social \& behavioral sciences $\left(2^{\text {nd }}\right.$ ed., Vol. 21 , pp. 48-54). Oxford: Elsevier.

Seligman, M.E., Abramson, L.Y., Semmel, A., \& Von Baeyer, C. (1979). Depressive attributional style. Journal of Abnormal Psychology, $88(3), 242-247$.

Seligman, M.E., \& Schulman, P. (1986). Explanatory style as a predictor of productivity and quitting among life insurance sales agents. Journal of Personality and Social Psychology, 50(4), 832-838.
Tiedens, L.Z., \& Linton, S. (2001). Judgment under emotional uncertainty: The effects of specific emotions on information processing. Journal of Personality and Social Psychology, 81(6), 973-988. http://dx.doi. org/10. 1037/0022-3514.81.6.973

Triandis, H.C. (2001). Individualism-collectivism and personality. Journal of Personality, 69(6), 907-924.

Van der Pligt, J. (2015). Psychology of decision making. In J.D. Wright (Ed.), International encyclopedia of the social \& behavioral sciences ( $2^{\text {nd }}$ ed., pp. 917-922). Oxford: Elsevier.

Weiner, B. (1986). An attributional theory of motivation and emotion. New York: Springer-Verlag.

Weiner, B. (2010a). The development of an attribution-based theory of motivation: A history of ideas. Educational Psychologist, 45(1), 28-36.

Weiner, B. (2010b). Attribution theory. In P. Peterson, E. Baker, \& B. McGaw (Eds.), International encyclopedia of education (Vol. 6 , pp. 558-563). Oxford: Elsevier.

Weiner, B. (2015). Heider, Fritz (1896-1988). In J.D. Wright (Ed.), International encyclopedia of the social \& behavioral sciences $\left(2^{\text {nd }} e d\right.$. pp. 750-754). Oxford: Elsevier.

Zeelenberg, M., Nelissen, R.M.A., Breugelmans, S.M., \& Pieters, R. (2008). On emotion specificity in decision making: Why feeling is for doing. Judgment and Decision Making, 3(1), 18-27.

Zuckerman, M. (1979). Attribution of success and failure revisited, or the motivational bias is alive and well in attribution theory. Journal of Personality, 47, 245-287.

\section{ACKNOWLEDGEMENTS}

The authors wish to express their sincere gratitude to the editor and anonymous reviewers of this manuscript who assisted us in fine-tuning the paper. We give our special thanks to the participants who willingly took part in this study. 
Appendix 1.

Appendices

\section{Sample of Attribution Scale}

1. Your exam scores are announced, and your friend has got a low score, though $\mathrm{s} / \mathrm{he}$ had studied hard. What do you think the possible cause might be?

a. He/she is not very bright.

\begin{tabular}{|ccccc|}
\hline 1 & 2 & 3 & 4 & 5 \\
Strongly disagree & Disagree & Neutral & Agree & Strongly agree \\
& & & \\
\hline
\end{tabular}

b. The professor seems to have had an ax to grind with the student, and has given him/her a low score.

\begin{tabular}{|ccccc|}
\hline 1 & 2 & 3 & 4 & 5 \\
Strongly disagree & Disagree & Neutral & Agree & Strongly agree \\
& & & \\
\hline
\end{tabular}

\section{Appendix 2.}

Sample of Emotioncy Scale

\begin{tabular}{|c|c|c|c|c|c|c|}
\hline $\begin{array}{l}\text { 1. Your } \\
\text { exam } \\
\text { scores are } \\
\text { announced, } \\
\text { and your } \\
\text { friend has } \\
\text { got a low } \\
\text { score, } \\
\text { though s/he } \\
\text { had studied } \\
\text { hard. }\end{array}$ & $\begin{array}{l}\text { I have } \\
\text { never } \\
\text { been in } \\
\text { this } \\
\text { situation. }\end{array}$ & $\begin{array}{l}\text { I have heard } \\
\text { that some } \\
\text { people get a } \\
\text { low score } \\
\text { on an exam, } \\
\text { though they } \\
\text { study hard. }\end{array}$ & $\begin{array}{l}\text { I have heard } \\
\text { and seen } \\
\text { that people } \\
\text { get a low } \\
\text { score on an } \\
\text { exam, } \\
\text { though they } \\
\text { study hard. }\end{array}$ & $\begin{array}{l}\text { I have } \\
\text { heard, seen, } \\
\text { and been in } \\
\text { touch with } \\
\text { people who } \\
\text { have got a } \\
\text { low score } \\
\text { on an exam, } \\
\text { though they } \\
\text { had studied } \\
\text { hard. }\end{array}$ & $\begin{array}{l}\text { I myself } \\
\text { have been in } \\
\text { this } \\
\text { situation, } \\
\text { and have } \\
\text { got a low } \\
\text { score on an } \\
\text { exam, } \\
\text { though I had } \\
\text { studied } \\
\text { hard. }\end{array}$ & $\begin{array}{l}\text { I have } \\
\text { experienced, } \\
\text { and } \\
\text { researched } \\
\text { deeply on the } \\
\text { ones who } \\
\text { have got a } \\
\text { low score on } \\
\text { an exam, } \\
\text { though they } \\
\text { had studied } \\
\text { hard. } \bigcirc\end{array}$ \\
\hline $\begin{array}{l}\text { How I feel } \\
\text { about this } \\
\text { situation }\end{array}$ & & $\begin{array}{l}\text { Extremely } \\
\text { negative } \\
\text { Negative } \\
\text { Neutral } \\
\text { Positive } \\
\text { Extremely } \\
\text { positive }\end{array}$ & $\begin{array}{l}\text { Extremely } \\
\text { negative } \\
\text { Negative } \\
\text { Neutral } \\
\text { Positive } \\
\text { Extremely } \\
\text { positive }\end{array}$ & $\begin{array}{l}\text { Extremely } \\
\text { negative } \\
\text { Negative } \\
\text { Neutral } \\
\text { Positive } \\
\text { Extremely } \\
\text { positive }\end{array}$ & $\begin{array}{l}\text { Extremely } \\
\text { negative } \\
\text { Negative } \\
\text { Neutral } \\
\text { Positive } \\
\text { Extremely } \\
\text { positive }\end{array}$ & $\begin{array}{l}\text { Extremely } \\
\text { negative } \\
\text { Negative } \\
\text { Neutral } \\
\text { Positive } \\
\text { Extremely } \\
\text { positive }\end{array}$ \\
\hline $\begin{array}{l}\text { My } \\
\text { exposure to } \\
\text { this } \\
\text { situation }\end{array}$ & & $\begin{array}{l}\text { Extremely } \\
\text { low } \\
\text { Low } \\
\text { Normal } \\
\text { High } \\
\text { Extremely } \\
\text { high }\end{array}$ & $\begin{array}{l}\text { Extremely } \\
\text { low } \\
\text { Low } \\
\text { Normal } \\
\text { High } \\
\text { Extremely } \\
\text { high }\end{array}$ & $\begin{array}{l}\text { Extremely } \\
\text { low } \\
\text { Low } \\
\text { Normal } \\
\text { High } \\
\text { Extremely } \\
\text { high }\end{array}$ & $\begin{array}{l}\text { Extremely } \\
\text { low } \\
\text { Low } \\
\text { Normal } \\
\text { High } \\
\text { Extremely } \\
\text { high }\end{array}$ & $\begin{array}{l}\text { Extremely } \\
\text { low } \\
\text { Low } \\
\text { Normal } \\
\text { High } \\
\text { Extremely } \\
\text { high }\end{array}$ \\
\hline
\end{tabular}

